\title{
Boerhaave syndrome and black esophagus
}

\section{Síndrome de Boerhaave e esôfago preto}

\author{
Grigoriy Emil Gurvits' \\ New York University School of Medicine/Langone Medical Center, New York, United States
}

\author{
'MD, FACP, FACG. Clinical Associate Professor, \\ Department of Medicine, Division of \\ Gastroenterology, New York University School \\ of Medicine/Langone Medical Center, New York, \\ United States.
}

Dear Editor,

It was with great interest that I read an article by Dr. Dinic and colleagues on Boerhaave syndrome in the latest issue of your journal. ${ }^{1}$ They describe a rare case of spontaneous esophageal perforation in the setting of hematemesis in association with duodenal ulcer and black esophagus.

Boerhaave syndrome is an unusual entity in clinical medicine that was historically described by classical physical examination findings of the Mackler triad (vomiting, chest pain and subcutaneous emphysema), Hamman's mediastinal crepitus with heartbeat and pneumomediastinum on X-ray imaging. Computed tomography scans showing Gastrografin extravasation are diagnostic on call to the operating room. ${ }^{2}$ Patients typically appear tachypneic and acutely ill.

The case of esophageal perforation presented by Dinic et al. is intriguing for several reasons, primarily because of the presence of a rare finding of distal black esophagus on postmortem examination. Black esophagus or acute esophageal necrosis is a syndrome that is classically characterized by a distal esophagus with circumferential black appearance of varying proximal extent. It presents clinically with gastrointestinal hemorrhage and is often associated with duodenal ulcer disease. ${ }^{3-5}$ The patient's clinical history and a four day prodrome may be a clue to the development of black esophagus.

It is true that profound retching with a sudden rise in intraesophageal pressure against a closed cricopharyngeus may result in spontaneous distal esophageal perforation, as seen in Boerhaave syndrome. On the other hand, blind passage of the nasogastric tube in the setting of a necrotic esophagus would potentially cause a longitudinal tear of similar appearance at the weak point just above the gastroesophageal junction. In fact, such a procedure should be avoided. ${ }^{4}$ It is also conceivable that repeated vomiting in a patient with black esophagus may result in Boerhaave syndrome. If so, this would be the first such occurrence described in the literature.

It is difficult to retrospectively point out the correct underlying diagnosis in this unfortunate case, but the possibility of an iatrogenic esophageal tear should be considered in this patient with concurrent finding of black esophagus. 


\section{REFERENCES}

1. Dinic BR, llic G, Rajkovic ST, Stoimenov TJ. Boerhaave syndrome - case report. Sao Paulo Med J. 2016;12:0. [Epub ahead of print]

2. Gurvits GE. Education and imaging. Gastrointestinal:"Walk in the snow": Boerhaave syndrome. J Gastroenterol Hepatol. 2011;26(1):207.

3. Gurvits GE, Cherian K, Shami MN, et al. Black esophagus: new insights and multicenter international experience in 2014. Dig Dis Sci. 2015;60(2):444-53.

4. Gurvits GE. Black esophagus: acute esophageal necrosis syndrome. World J Gastroenterol. 2010;16(26):3219-25.

5. Gurvits GE, Shapsis A, Lau N, Gualtieri N, Robilotti JG. Acute esophageal necrosis: a rare syndrome. J Gastroenterol. 2007;42(1):29-38.

Sources of funding: None

Conflict of interest: None

Date of first submission: December 27, 2016

Last received: December 27, 2016

Accepted: January 2, 2017

\section{Address for correspondence:}

Department of Medicine, Division of Gastroenterology, New York University School of Medicine/Langone Medical Center,

240 East 38th Street, New York, NY 10016, USA

Tel. +1-212-263-3095

Fax. +1-212-263-3096

E-mail: g_g@hotmail.com

\section{RESPONSE TO LETTER TO THE EDITOR}

\section{Biljana Radovanovic Dinic', Goran Ilic", Snezana Tesic Rajkovic ${ }^{\text {III }}$ Tatjana Jevtovic Stoimenov ${ }^{\text {IV }}$}

'MD. Associate Professor and Attending Physician, Medical School, University of Niš, and Gastroenterology and Hepatology Clinic, Niš Clinical Center, Niš, Serbia. "MD. Associate Professor, Medical School, University of Niš, and Institute of Forensic Medicine, Niš, Serbia.

"'MD. Attending Physician, Gastroenterology and Hepatology Clinic, Niš Clinical Center, Niš, Serbia.

IvMD. Associate Professor, Medical School, University of Niš, and Institute of Biochemistry, Niš, Serbia.

Dear Sir,

I am glad that our work has sparked your interest. The study presents a case of a patient with spontaneous rupture of the esophagus caused by vomiting. In Figure 2, we presented the esophagus with its surface covered with blood (not washed). The wall of the esophagus was not necrotized (shown histopathologically), and it was not a black esophagus. ${ }^{2,3}$ Setting the nasogastric tube in this case was risky; however, it was necessary in order to evacuate the heavy liquid content of the stomach (detected on abdominal ultrasound), as well as to perform esophagogastroduodenoscopy (EGD). The patient had the same symptoms before placing the probe and after removing it (before EGD), and so we ruled out the possibility that she might have caused the rupture herself.

\section{REFERENCES}

1. Dinic BR, llic G, Rajkovic ST, Stoimenov TJ. Boerhaave syndrome - case report. Sao Paulo Med J. 2016;12:0. [Epub ahead of print]

2. Kimura Y, Seno H, Yamashita Y. A case of acute necrotizing esophagitis. Gastrointest Endosc. 2014;80(3):525-6.

3. Gurvits GE, Cherian K, Shami MN, et al. Black esophagus: new insights and multicenter international experience in 2014. Dig Dis Sci. 2015;60(2):444-5. 